\title{
A Study on the Prevalence of Giardia lamblia Infection in Children among the Population of Dhanbad, A Coal Field Area
}

\author{
Binay Kumar Singh, Siyavar Sharan*, Nitesh Kumar Jaiswal and Rohit Kumar \\ Department of Microbiology, Patlipura Medical College and Hospital, Dhanbad, \\ Jharkhand 826005, India \\ *Corresponding author
}

\begin{abstract}
A B S T R A C T
Keywords

Giardia lamblia, Stool microscopy, Children, socioeconomic, Coal field

Article Info

Accepted:

26 June 2018

Available Online:

10 July 2018

Giardiasis is one of the most common parasitic infestations in children and its prevalence is high in developing countries. It is associated with low socioeconomic level, poor sanitary conditions, usage of contaminated drinking water and poor personal hygiene. A total of 667 stool sample from children $(<12$ yrs) were examined for stool microscopy. In total $33.14 \%$ samples were positive for Giardia lamblia. The highest prevalence of G. lamblia was observed in age group 4-8 yrs (34.59\%), followed by age group 1-3 yrs (33.55\%) and age group 912 yrs $(31.90 \%)$. We have observed high prevalence rate of Giardiasis in children of this coal field area. Prompt measures are required to lower the prevalence rate of these parasitic infestations.
\end{abstract}

\section{Introduction}

Intestinal parasites infect approximately 3 billion people worldwide, leading to augmented risk of developmental deficiencies, and even deaths (1). In tropical countries, parasitic infection is a common cause of morbidity along with mortality (2). Its incidence is predominantly high in developing countries owing to the poor sanitary conditions, usage of contaminated drinking water and poor personal hygiene(3). Giardiasis is one of the most common parasitic infestations in children which are caused by a Zoonotic protozoan called Giardia lamblia (4). This parasite affects humans and domestic as well as wild animals (5). World Health Organization had reported that, since 1988, there were over 280 million new cases of Giardia lamblia infection observed every year in Africa, Latin America and Asia(1). It is also associated with socioeconomic level of a country and its prevalence ranges from 2 to $7 \%$ in most of industrialized regions and reaching $40 \%$ in developing countries(6) This diseases may have both immediate and longterm consequences including chronic diarrhoea with or without dehydration and intestinal malabsorption, recurrent abdominal pain, and weight loss (7). It has been currently related to chronic fatigue post infectious irritable bowel syndrome and particularly, in 
early childhood, poor cognitive function and failure $(8,9)$.

Giardiasis can be diagnosed through identification of cysts, trophozoites and Giardia-specific antigens in faecal samples. Several faecal tests are available. Comparison of faecal diagnostic methods is problematic due to the lack of a true gold standard reference method (10). The ovum and parasite method is the currently-accepted gold standard method despite its inferior sensitivity particularly when only a single faecal sample is available for analysis (11). The main objective of this study was to determine the prevalence of Giardia infection in children staying in coal field area.

\section{Materials and Methods}

The study was conducted at Patliputra medical college and hospital, Dhanbad. This city has some of the largest coal mines and is called coal capital of India. It is the second most populated city in Jharkhand. Due to long time mining, low socioeconomic perspective and poor sanitary condition, this area is more vulnerable for infectious diseases. A total of 667 stool sample between June 2017 and May 2018 from children with complains of loose stool (motion frequency more than 3 per 24 hrs) was included for this study. A questionnaire form was developed from all of the patients comprising of complete medical and living history including; economic status, hygiene behaviour, source of drinking water and tools pertaining to sanitation and primary complaint. The samples were collected using sterile plastic containers and gross examination was made for density and presence of worms or their segments. The samples were then transferred in $0.85 \%$ saline solution and microscopic examination was done on the same day by direct wet smears in $0.85 \%$ saline and 5\% Lugol's iodine (12). Prevalence along with respective $95 \%$ confidence interval (CI) by Binomial exact method was calculated. Chi square analysis was conducted to test the association of prevalence with age and sex. $95 \%$ confidence interval was calculated to express the strength of association among sex, age and diagnostic results.

Inclusion criteria: All children up to $12 \mathrm{yrs}$ with diarrhoea except neonates.

Exclusion criteria: Neonates and all children without diarrhoea.

\section{Results and Discussion}

The overall prevalence of $G$. lamblia along with prevalence in both genders is presented in Table 1. In total, 221 (33.13\%) samples were found positive for Giardia. Higher prevalence of parasites was observed in males $(35.40 \% \mathrm{CI}=3.52)$ in comparison to females (31.21\% CI= 3.33). Table 2 represents the prevalence of giardiasis in different age groups. The highest prevalence of G.lamblia was observed in age group 4-8 (34.59\%), followed by age group 1-3 $(33.55 \%)$ and age group 9-12 (31.90\%).

The present manuscript depicts higher prevalence $(33.13 \%)$ of Giardia lamblia infection in the studied population. Similar to this study, Khan et al., have observed the prevalence of $37.7 \%$ Giardiasis among the afghan refugee population in Pakistan (13). Another investigator from Nawabshah (Sindh), rural Southern India and Argentina have also found higher prevalence of Giardia lamblia infection which is in accordance to the present study $(14,15,16)$.Higher incidence of this parasite infection was observed in males. Statistical analysis also specified that males were more likely to be infected by this parasite. However Awasthi et al., have not found significant association of sex of patient and diarrhoea in parasitic infection among 
children (17).We have also observed the highest rate of prevalence of Giardia infection in the age group of 4 to 8years followed with age group 1-3 years and 9- 12 years. Nazari et.al., have found highest rate of prevalence is related to the age group of 4 to 6 years and the lowest rate related to age group of 0 to 2 years(18). In a study done by Saiari et al., have found the infestation rate of Giardiasis in children over 2 years was $10.4 \%$, which had the highest rate of prevalence compared to other intestinal parasites (19).This rate was lower than our one, due to the difference between age range of the participants and the size of the sample. In a another study done in the kindergartens and primary and secondary schools of Kashan city over5 to 15 years old students, the infestation rate of Giardiasis was $38.5 \%$, which $17 \%$ of the cases lacked clinical symptoms (20). A study in Havana city on the kids 1 to 5 years old, the infection rate of Giardiasis was 54.6\%, introducing Giardiasis as the most common pathogen in the age range of 2 to 4 years (21).

Table.1 Absolute prevalence with relationship of gender preponderance

\begin{tabular}{|c|c|c|c|}
\hline Gender & Positive/tested & Prevalence \% & 95\% CI \\
\hline Male & $108 / 305$ & 35.40 & $31.88-38.92$ \\
\hline Female & $113 / 362$ & 31.21 & $27.88-34.54$ \\
\hline
\end{tabular}

Table.2 Absolute prevalence with relationship of age

\begin{tabular}{|c|c|c|c|}
\hline Age group in yrs & Positive/tested & Prevalence $\%$ & 95\% CI \\
\hline $\mathbf{1 - 3}$ & $51 / 152$ & 33.55 & $29.99-37.11$ \\
\hline $\mathbf{4 - 8}$ & $73 / 211$ & 34.59 & $31.07-38.11$ \\
\hline $\mathbf{9 - 1 2}$ & $97 / 304$ & 31.90 & $28.57-35.23$ \\
\hline
\end{tabular}

The results of present study show the prevalence of Giardiasis in the children of different age groups residing in coal field area. It can be concluded from this study that Giardia infections are common in Dhanbad district, Jharkhand, India. Prompt preventive measures should be taken for the eradication of high infection rate that should include ensuring clean water supply, public health education, sanitation facilities, promoting personal hygiene and especially periodic deworming of the children.

\section{References}

1. WHO. 1996. Fighting Disease, Fostering Development, World Health Organization. Geneva.

2. Al-Ballaa SR, M Al-Sekeit, SR Al-Balla, et.al. 1993. Prevalence of pathogenic intestinal parasites among preschool children in Al-Medina district, Saudi Arabia. Dhu Al Qa'da. 13: 259-63.

3. Hussain SM, Raza MI and Naeem S.1997. Prevalence of intestinal parasites in northern areas of Pakistan (Baltistan division -Skardu). Biomedica. 5: 60-3.

4. Keating PJ. 1998 Giardiasis Figin Textbook of paediatric infectious dis. 14th ed. Philadelphia: Saunders. 2400-04.

5. Adam RD. 2001. Biology of Giardia lamblia. Clinical Microbiology Rev. 14:447-475.

6. Upcroft P. 2001 Meeting report: Anaerobic Protozoan Parasites, Prague, Czech Republic, July 15-19, 2001. Protist.152 (4): 241-242.

7. Escobedo A, Almirall P, Robertson L J et 
al., 2010. Giardiasis: the ever-present threat of a neglected disease, Infectious Disorders - Drug Targets. 10(5): 329 348,

8. Syed A. Alia and David R. 2003. Giardia intestinalis. Hill a Current Opinion in Infectious Diseases. 16:453-460.

9. Chatterjee BD, Thawani G and Sanyal. 1989. SN Etiology of acute childhood diarrhoea in Calcutta. Trop Gastroenterol. 10:158- 66.

10. Weitzel T, Dittrich S, Mohl I, et.al. 2006. Evaluation of seven commercial antigen detection tests for Giardia and Cryptosporidium in stool samples. Clin Microbiol Infect.12:656-9.

11. Hanson KL, Cartwright CP. 2001. Use of an enzyme immunoassay does not eliminate the need to analyze multiple stool specimens for sensitive detection of Giardia lamblia. $J$ Clin Microbiol. 39:474-7.

12. Cable RM. 1985. An illustrated manual of parasitology. Surjeet Publication, New Delhi, India. 242-246.

13. Khan AU, Naz A Gul, Hussain M H et.al., 2015. Prevalence of Giardia intestinalis and Hymenolepis nana in Afghan refugee population of Mianwali district, Pakistan. African healh sciences. 15(2):394-400.

14. Akhund AA. 1994. Frequency and pattern of pathogenic intestinal parasites in Nawabshah Sindh. Pakistan Journal of Pathology. 5: 39-42.

15. Kang G, Mathew MS, Rajan DP, et.al., 1998. Prevalence of intestinal parasites in rural southern Indians. Tropical Medicine and International Health. 3: 70-75.
16. Gamboa MI, Basualdo JA, Kozubsky L, Costas E and Cueto Rua E. 1998; Prevalence of intestinal parasitosis within three population groups in $\mathrm{La}$ plata, Argentina. European Journal of Epidemiology. 14: 55-6.

17. Awasthi and Pande V.K. 1997 prevalence of malnutrition and intestinal parasites in preschool slum children in Lucknow; Indian pediatrics volume 34 july.

18. Nazari N, Fatahi M and Sadeghi M.2015. A study of the prevalence of Giardiasis in children of the kindergartens of Islam Abad Gharb city, Iran. Sch. J. App. Med. Sci.; 3(9C):3307-3310.

19. Sayyari AA, Imanzadeh F, Bagheri Yazdi SA et.al 2005. Prevalence of intestinal parasitic inections in the Islamic Republic of Iran. East Mediter Health J. 11(3): 37783.

20. Talebian A, Talari SF and Parvaresh S. 2001. A study of the prevalence of Giardiasis and its clinical symptoms in the children 5 to 15 years old in Kashan city in 1997. Faiz Research and Scientific Journal. 12:59-64.

21. Mendoza D, Nunez FA, Escobedo A, et.al., 2001 Torres D, et al.; Intestinal parasitic infection in 4 child day- care centers located in San Miguel pardon municipality, Havanan City. Rev Cubana Med Trop.; 53(3): 189-93.

\section{How to cite this article:}

Binay Kumar Singh, Siyavar Sharan, Nitesh Kumar Jaiswal and Rohit Kumar. 2018. A Study on the Prevalence of Giardia lamblia Infection in Children among the Population of Dhanbad, A Coal Field Area. Int.J.Curr.Microbiol.App.Sci. 7(07): 3552-3555. doi: https://doi.org/10.20546/ijcmas.2018.707.412 